This item was submitted to Loughborough's Research Repository by the author.

Items in Figshare are protected by copyright, with all rights reserved, unless otherwise indicated.

\title{
Enabling inertial response in utility-scale battery energy storage system
}

PLEASE CITE THE PUBLISHED VERSION

http://dx.doi.org/10.1109/ISGT-Asia.2016.7796453

PUBLISHER

(c) IEEE

VERSION

AM (Accepted Manuscript)

\section{PUBLISHER STATEMENT}

(c) 2016 IEEE. Personal use of this material is permitted. Permission from IEEE must be obtained for all other uses, in any current or future media, including reprinting/republishing this material for advertising or promotional purposes, creating new collective works, for resale or redistribution to servers or lists, or reuse of any copyrighted component of this work in other works.

\section{LICENCE}

All Rights Reserved

\section{REPOSITORY RECORD}

Gonzalez-Longatt, Francisco, and Samir M. Alhejaj. 2019. "Enabling Inertial Response in Utility-scale Battery Energy Storage System". figshare. https://hdl.handle.net/2134/24270. 


\section{Enabling Inertial Response in Utility-Scale Battery Enegery Storage System}

\author{
Francisco M. Gonzalez-Longatt \\ Electronic, Electrical and Systems Engineering School \\ Loughborough University \\ Loughborough, UK \\ fglongatt@fglongatt.org
}

\begin{abstract}
This paper presents a simple controller to enable the inertial response of utility-scale battery energy storage system (BESS). Details of the BESS modeling are presented in this paper. The main contribution of this paper is to demonstrate that inertial controller in BESS help to reduce change to the rate of change of frequency (RoCoF), providing frequency support and improving the system frequency response. The effect of changes in the gain of the synthetic inertial on the system frequency response is investigated using time domain simulations based on DIgSILENT PowerFactory. The time-domain simulations show the advantages of using the inertial controller in BESS to reduce the initial drop in the system frequency. The battery charge control must be improved in order to avoid undesirable battery recharge during critical stages of the frequency response. This is especially dangerous because it can create a second system
\end{abstract}

Keywords- Battery energy storage system (BESS), frequency response, inertial response, power converter.

\section{INTRODUCTION}

One important challenge of future power systems is the massive deployment of power converters. The high power converters decouple the energy sources from the pre-existent power grids, negatively affecting the system performance. During a system frequency disturbance the balance between the power generation and demand is lost, as a consequence, the system frequency will change at a rate initially determined by the total system inertia $\left(H_{T}\right)$ and the size of the power imbalance $(\triangle P)$. System inertia is proportional to the sum of stored energy $\left(E_{c}\right)$ of the rotating masses of machines (generators and motors) which are directly connected to the electricity grid.

The installed power capacity (MW) of future power systems will increase but the effective total system inertia $\left(\underline{H}_{T}\right)$ will be the same nowadays, as a consequence, the system will have more demand but the system frequency response as today. This situation is caused by the new generation units, energy storage systems and HVDC interconnection based on high power converters, all of them tend to decouple the real inertia $(H)$ and the AC grid. The result is deeper frequency excursions during system disturbances [1]. Lower system inertia increases the probability of fast system changes and instability arising from progressively small disturbances that could lead to severe faults or loss of generation or demand. It is expected a substantial decrease in the ability to overcome system

\author{
Samir M. Alhejaj \\ Electronic, Electrical and Systems Engineering School \\ Loughborough University \\ Loughborough, UK \\ s.m.alhejaj@lboro.ac.uk
}

frequency's disturbances, based on a decreased inertial response with overwhelming consequences for system frequency security and reliability.

Several governments around the world have established very ambitious targets to migrate to a low carbon economy and achieving massive penetration levels of electricity production based on renewable energy sources (RES) in the coming years. The EU's Renewable energy directive sets a binding target of $20 \%$ final energy consumption from renewable sources by 2020. The European Energy Union (EEU), as set out in the recent framework strategy migrating the energy systems to ensure secure, affordable and climatefriendly energy. EU's energy and climate targets for 2030: at least $40 \%$ domestic reduction in greenhouse gas emissions compared to 1990 , at least $27 \%$ improvement of energy efficiency, an electricity interconnection target of $10 \%$ at least $27 \%$ of the share of renewable energy consumed in the EU. To cope with those targets, the interconnected power system of Continental Europe (CE) faces a rapid change in the structure and geographic distribution of generation. The increase of power converter based RES is decreasing the share of synchronous generation and decreasing the locally available system inertia. The future challenge regarding frequency stability will differ between countries in the CE. However, the $\mathrm{CE}$ power system is highly interconnected with high inertia shared across countries and scenarios for the future indicate a Rate of Change of Frequency (RoCoF) higher than $2 \mathrm{~Hz} / \mathrm{s}$ is possible [1]. RES, particularly offshore wind power, will be a major element of the UK's transition to meet its targets for carbon reduction and renewable penetration in 2030, it will result in a significant decrease of system inertia (also shortcircuit levels). System inertia, in the UK, is expected to reduce between 2016 and 2035 during periods of low demand and/or high renewable generation. The System Operability Framework (SOF) [2] of the Great Britain (GB) transmission system operator (TSO), National Grid Electricity Transmission plc $(\mathrm{NG})$, demonstrates that the required amount of frequency response in future scenarios will increase by 3 to 4 times from the current level [2].

There are several options to mitigate the challenges of reduced system inertia. One of the possible solutions is logically increasing the total system inertia (where is economically and technically possible), but also open opportunities for new providers of frequency response services. 
Energy storage system (ESS) such as flywheel systems (FS) and certain types of batteries energy storage systems (BESS) have the technical capability to offer frequency response services which may be much faster than traditional providers.

$B E S$ based on power electronic converter has the ability of a very fast deployment (scale of few mili-secs) but also, the controller used in the power converter system (PES) allow to control the shape of the frequency response in different ways. Several shapes of frequency response could be used, e.g. maximum inertial response, $\mathrm{ROCOF} /$ frequency, disturbance following functions, etc.

The objective of this paper is to present a controller to enable the inertial response of utility-scale battery energy storage system (BESS). The structure of this paper is based on five Sections. Section II describes the status of BESS in GB and Section III presents the main aspects of BESS modeling including the concept of synthetic inertia and show how it can be used create an inertial response in BESS. Section IV shows the results of simulations that define the impact of synthetic inertia controller on the system frequency response of a test system. Finally, the advantages of this controller are discussed in Section V.

\section{BATTERY ENERGY STORAGE IN GB}

National Grid plc (NG) is in charge of the frequency control of the Great Britain (GB) power system. The NG's Security and Quality of Supply Standard requires the system frequency to me maintained at $50 \mathrm{~Hz} \pm 200 \mathrm{mHz}$ [3] save in abnormal or exceptional circumstances. NG uses frequency response services to manage all credible circumstances that might result in frequency variations. The Security and Quality of Supply Standard (SQSS) [4] defines the frequency standards in the GB system. The largest normal loss of generation, specified as $\Delta P=1,32 \mathrm{GW}$ (from April 2014) and it is expected to increases to $\Delta P=1,8 \mathrm{GW}$ between $2019-2021$. For any loss larger to the normal loss of generation, the event is referred as an emergency condition, and the automatic lowfrequency load shedding (UFLS) will start at $48.8 \mathrm{~Hz}$. It is the protection scheme that is adjusted to disconnect the customer power demand; if this is triggered up to 9 stages are used to disconnect up to $60 \%$ of the load demand.

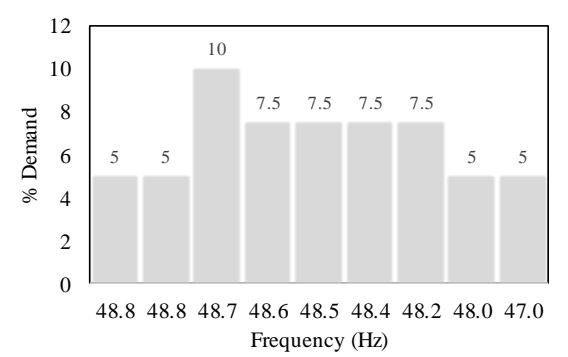

Fig. 1. Setting of demand disconnection $(\%)$ versus frequency $(\mathrm{Hz})$ of the automatic UFLS.

Fig. 1 shows the percentage of demand disconnection in the transmission area based on the under frequency (based on Table CC.A.5.5.1a [5]). National Grid's System Operability Framework (SOF) [2] describes the future needs of the transmission network. It provides a holistic view of how changes in the energy landscape described in our Future Energy Scenarios (FES) [6] will impact the operability of GB power networks. The SOF analysis indicates the system inertia $\left(H_{T}\right)$ continues to decline because of the lack of synchronous thermal power stations and high volume of converters connected generation technologies such as solar PV, wind power, and import across our High Voltage Direct Current (HVDC) interconnectors. Fig. 2 shows the forecasted evolution of the total system inertia of GB system for the next 20 years.

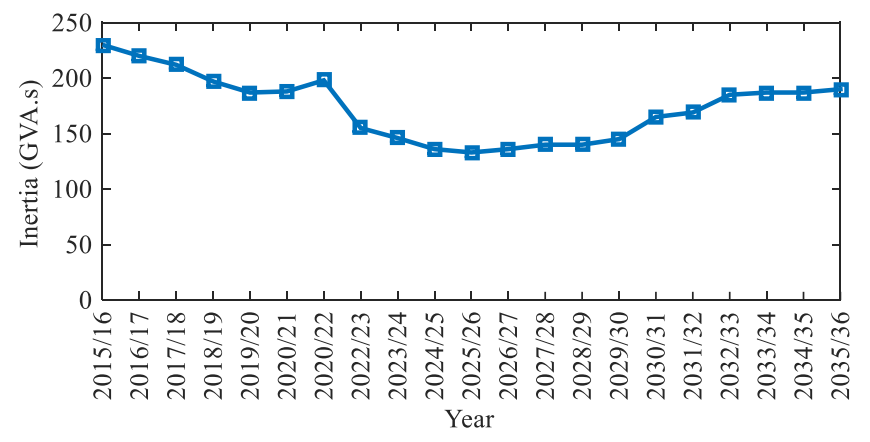

Fig. 2. Minimum system inertia including the contribution from Embedded Generation [2].

The UK government has the plan to close all coal-fired power stations by 2025 and restrict their use by 2023 . Also, the UK energy from coal hits zero for the first time in over 100 years, in fact, the UK coal power generation hits $0 \%$ couple times on May 2016. However, the decommissioning of several fossil fuel power stations will reduce the total inertia provided by classical synchronous generators, and negatively affecting the system frequency response of the GB system. Around 5 percent of the UK's electricity needs are currently met through offshore wind (June 2016), and there are more than $10 \mathrm{GW}$ of offshore wind power generating, under construction. It is expected that the UK will generate 10 percent of its electricity from offshore wind by 2020. On the other hand, UK is expanding its power generation portfolio adding more the 3.2 GW nuclear power plant Hinkley Point C, it will provide 25 TWh a year or 7\% of today's UK demand, had originally been meant to open in 2017(?). The future generation mix of heavy inertia nuclear power plants and massive penetration of low/none inertia wind power will negatively affect the generation system frequency response. NG has forecasted the decrease of the total system inertia and it is looking into a solution for it, the use of BESS as providers of fast frequency response services is a realistic option.

The current status (June 2016) of the electricity energy storage systems in GB is oriented to the utility-scale sector. The residential-scale storage is still not economically viable, and the level of commercial and industrial storage, although unknown, is thought to be quite low. GB has around 30 operational battery energy storage (BES) projects, many of them are demonstration projects, and with only a few of them are operational projects larger than $1 \mathrm{MW}$ in size. The $U K$ Power Networks Smarter Network Storage (SNS) [7] is the most publicized GB battery energy storage project. This project is led by the district network operator (DNO) UK Power 
Networks (UKPN) and comprises 6MW/10MWh lithium-ion system located in Bedfordshire.

The largest BES project to date (May 2016) is Kilroot Advancion $^{\circledR}$ Energy Storage Array, this $10 \mathrm{MW}$ installation is led by AES UK \& Ireland and located adjacent to coal-fired Kilroot Power Station, located north of Belfast, Northern Ireland. The array utilizes over 53,000 Li-ion batteries arranged in 136 separate nodes and will enhance grid reliability by providing fast response ancillary services (such as frequency regulation) as part of the System Operator Northern Ireland (SONI) existing Harmonised Ancillary Services system. The $10 \mathrm{MW}$ installation is a crucial first step towards a planned 100 MW energy storage array [8]. Bulk storage or utility-scale on the transmission network (>50MW capacity) has potential in helping balance the network through both providing fast response reserve generation to meet demand and absorbing electricity at a time when the system is at risk of overload.

\section{MODELING OF BATTERY ENERGY STORAGE SYSTEM (BESS)}

An Electrical Energy Storage System (EESS) is a three-step process comprising a transformation of electrical energy into some other energy form; the storage of energy itself during a period of time; and the reconversion of the energy stored back into electrical energy. The model of EESS has two main subsystems: (i) a power conversion system (PCS) and an energy storage system (ESS).

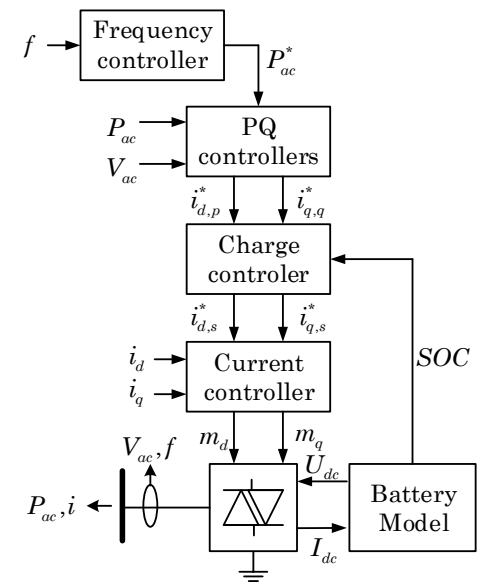

Fig. 3. A representative block diagram illustrating the Battery Energy Storage System (BESS) used in this paper.

The energy storage system model which represents the system that store/restore energy. Several technologies are used to convert/store electricity, they can be grouped according to the energy form that serves as the storage: mechanical, chemical, electrochemical, electrical, and thermal. In this paper, the ESS is based on electrochemical batteries. A power conversion system (inverter/rectifier) is included to transform the DC-voltage from the energy storage part to the AC-voltage conditions used in the power network. The PCS is equipped with a set of controllers, they are designed to enable specific functionalities interfacing the EES and the power network. A detailed description of those subsystems is presented in the next subsections.

\section{A. Power conversion system (PCS) model}

This paper is focused on the system frequency response, as a consequence, the main attention is on the control behavior of ac/dc PWM-converter instead of switching frequencies, or high frequencies phenomenon. Taking into account the previous considerations, the fundamental frequency model is used in this paper in order to model the two-level PWM converter which operated in a stator-voltage oriented $d q$ reference frame. $d$-axis represents the active and $q$-axis the reactive component. The line-line AC voltage (rms value, $V_{a c}$ $\left.=V_{a c, d}+j V_{a c, q}\right)$ and dc voltage $\left(U_{d c}\right)$ are related by:

$$
V_{a c, d}=\frac{\sqrt{3}}{2 \sqrt{2}} m_{d} U_{d c} \quad V_{a c, q}=\frac{\sqrt{3}}{2 \sqrt{2}} m_{q} U_{d c}
$$

where $m_{d}$ and $m_{q}$ are the real and imaginary part of the modulation index $\left(m=m_{d}+j m_{q}\right)$.

\section{B. Energy storage system (EES) model}

The electrochemical energy storage technologies make use of reversible electrochemical reactions to convert/store electricity. Examples of electrochemical energy storage technologies are batteries and super capacitors. The battery storage technology is one of the oldest electrochemical energy storage technologies. There are several batteries technologies commercially available in the market: Lead-acid batteries (Pbacid), lithium-ion batteries (Li-ion), nickel-cadmium batteries (NiCd), molten salt batteries like sodium-sulfur battery (NaS), aluminium-ion (Al-ion), vanadium redox battery (VRB), liquid metal batteries, Sodium-ion batteries (SIB). Several European distribution system operators are currently installing Li-ion batteries in stationary application to provide frequency control in regions with a high penetration of RES. NaS batteries are suited to grid-scale power storage applications. Redox-flow batteries separate the electrolyte, which is stored in a tank, from the electrodes and thus could be scaled up to very large energy capacities.

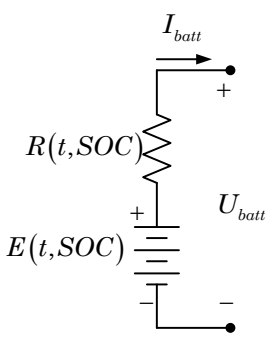

(a) Simple battery electric equivalent circuit.

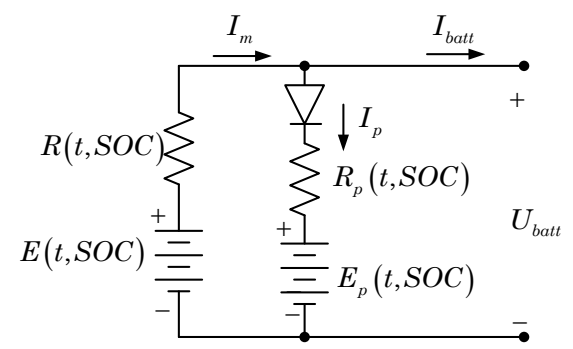

(b) Battery electric equivalent circuit taking into account a parasitic reaction.
Fig. 4. Circuit equivalent model representative of a battery [9].

Batteries using $\mathrm{Pb}$-acid provide a scalable technology base for providing short-term storage, in particular, frequency control. Modeling the battery is one of the most challenging situations in the energy storage system. However, since the battery is an electric bipole, were it linear, its more natural model would be constituted by an electromotive force $(E)$ in series with an internal impedance $(Z)$, both function of time $(t)$. In this paper the simple battery model shown in Fig. 4(a) is 
used. The state of charge (SOC) is calculated using an integrator which takes into account the current of the battery $\left(I_{b a t}\right)$ :

$$
U_{d c}=U_{\max } S O C+U_{\max }(1-S O C)-I_{b a t} Z_{i}
$$

where: $U_{\min }$ is the cell voltage discharged cell $(\mathrm{V}), U_{\max }$ is the maximum voltage of the battery cell (V).

\section{TABLE I. BATTERY MODELS PARAMETERS}

\begin{tabular}{l|c|c|c}
\hline \hline \multicolumn{1}{c|}{ Description } & Parameter & Unit & Value \\
\hline State of change & SOC & - & 0.8 \\
Single Cell Capacity & $W_{n}$ & $\mathrm{Ah}$ & 1.2 \\
Min. Voltage of empty cell & $U_{\min }$ & $\mathrm{V}$ & 12.00 \\
max. Voltage of full cell & $U_{\max }$ & $\mathrm{V}$ & 13.85 \\
Number of parallel connected cells & $N_{p}$ & - & 60 \\
Number of parallel connected cells & $N_{s}$ & - & 65 \\
Nominal BESS Voltage & $U_{n}$ & $\mathrm{~V}$ & 900 \\
Internal Resistance per cell & $Z_{i}$ & $\Omega$ & 0.001 \\
\hline
\end{tabular}

\section{Model of the battery charge controller}

The charge controller consists of two parts (Fig. 5): (i) Charging logic to achieve the SOC boundary conditions $\left(S O C_{\min } \leq S O C \leq S O C_{\max }\right)$, and (ii) current limiter to limits the absolute value of the current order according to limits $\left(I_{\min } \leq i \leq\right.$ $\left.I_{\text {max }}\right)$. The $d$-axis current has always the higher priority than the $q$-axis current. The signal $\Delta i$ is the difference of the reference $d$-axis current from the $P Q$-controller and $\left(i_{d, p}^{*}\right)$ the modified $d$ current from the charging logic $\left(i_{d, s}^{*}\right)$. The feedback of that signal to the $P Q$-controller prevents a windup of the PIcontroller.

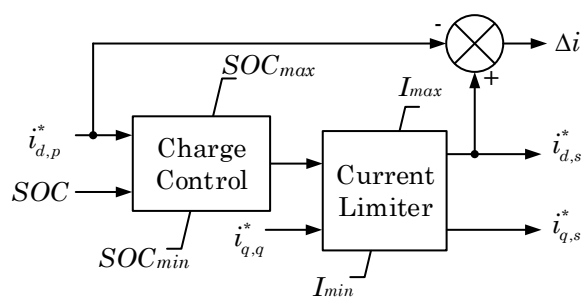

Fig. 5. Block diagram of the battery charge controller.

\section{Model of the current controller}

The input currents to the controller are the converter's ACcurrents expressed in a reference $d q$ frame $\left(i_{d}, i_{q}\right)$. The output signals $m_{d}$ and $m_{q}$ are defined in the same reference frame and transformed back to a global reference frame using the same reference angle. A proportional-integral (PI) control loop is used to regulate the $d$ and $q$-axis current components $\left(i_{d}, i_{q}\right)$ based on a PI controller regulating the battery charge, these are shown in Fig. 6.
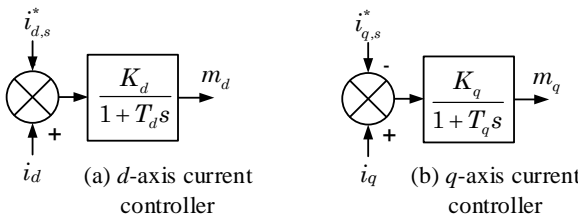

Fig. 6. Block diagram of the current controllers.

\section{E. Model of the PQ-Controller}

The controller for the active and reactive power is shown in Fig 7. The voltage (or $Q$ ) controller has a very slow current controller for set point tracking and a slope with a dead band for proportional voltage support.

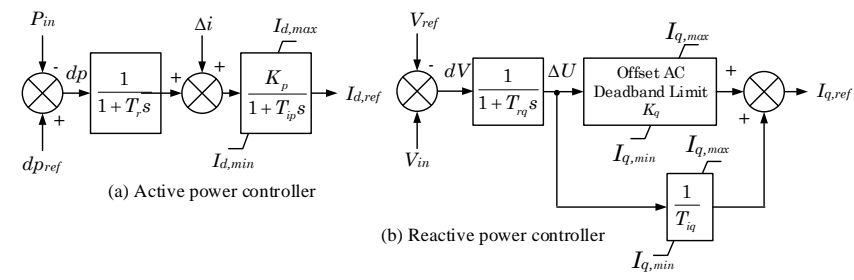

Fig. 7. Block diagram of the $P Q$-Controller.

TABLE II. BATTERY CHARGER CONTROLLER PARAMETERS

\begin{tabular}{|c|c|c|c|}
\hline Description & Parameter & Unit & Value \\
\hline Min charge current & Imin & p.u. & 0.1 \\
\hline Min state of charge & $S O C_{\min }$ & p.u. & 0.0 \\
\hline Max state of charge & $S O C_{\max }$ & p.u. & 1.0 \\
\hline Max absolute current & $I_{\max }$ & p.u & 1.0 \\
\hline
\end{tabular}

TABLE III. CURRENT CONTROLLER PARAMETERS

\begin{tabular}{l|c|c|c}
\hline \multicolumn{1}{c|}{ Description } & Parameter & Unit & Value \\
\hline Proportional gain, $d$-axis & $K_{d}$ & - & 0.1 \\
Integration time constant, $d$-axis & $T_{d}$ & sec & 0.001 \\
Proportional gain, $q$-axis & $K_{q}$ & - & 0.1 \\
Integration time constant, $q$-axis & $T_{q}$ & sec & 0.001 \\
\hline
\end{tabular}

TABLE IV. CURRENT CONTROLLER PARAMETERS

\begin{tabular}{l|c|c|c}
\hline \hline \multicolumn{1}{c|}{ Description } & Parameter & Unit & Value \\
\hline Filter time constant, $d$-axis & $T_{r}$ & $\sec$ & 0.05 \\
Filter time contact, $q$-axis & $T_{r q}$ & $\sec$ & 0.01 \\
Proportional gain, $d$-axis & $K_{p}$ & - & 2.00 \\
Integration time constant, $d$-axis & $T_{d}$ & $\mathrm{sec}$ & 0.10 \\
Deadband for proportional gain & $K_{d b}$ & - & 0.10 \\
Proportional gain, $q$-axis & $K_{q}$ & - & 2.00 \\
Integrator time constant, $q$-axis & $T_{q}$ & $\sec$ & 1.00 \\
Min. current, $d$-axis & $I_{d m i n}$ & $p . u$. & -1.00 \\
Min. current, $q$-axis & $I_{q \min }$ & $p . u$. & 1.00 \\
Max. current, $d$-axis & $I_{d \max }$ & p.u. & -1.00 \\
Min. current, $q$-axis & $I_{q \max }$ & p.u. & 1.00 \\
\hline
\end{tabular}

\section{F. Model of the Frequency Controller}

During a system frequency disturbance (SFD) the generation/demand power balance is lost, the system frequency will change at a rate initially determined by the total system inertia $\left(H_{T}\right)$. Power sources and EESS connected to the grid using full-rated power converters has the potential to provide a very fast frequency response. Several names have been using in the wind turbine industry to define the controllers to enable a power converter to mimic the inertial response of a synchronous generator: Artificial, Emulated, Simulated, or Synthetic Inertia.

The synthetic inertia concept allows a controller to the take the kinetic energy from the rotating mass in a wind turbine generator (WTG). This concept can be perfectly applied to BESS, but instead of taking kinetic energy from the rotating masses, the controller enables to discharge the battery in a controlled way producing an additional power in the form of inertial power. 
The synthetic inertia controller can be understood as a simple loop that increases the electric power output of the PCS during the initial stages of a significant downward frequency event. The inertial power or power produced during the system frequency disturbance is calculated using the equivalent to the swing equation of a synchronous generator [10]:

$$
\Delta P=2 f H_{s y n} \frac{d f}{d t}
$$

where $H_{\text {syn }}$ represent the value of the synthetic inertia (sec) and $f$ is system frequency (p.u.). Implementation of synthetic inertia controller is depicted in Fig. 8 , where $P^{*}{ }_{a c}=\Delta P$. It is important to point out the synthetic inertia $H_{s y n}$, represent the gain of the proportional controller in the frequency controller. The gain of the frequency controller is could be any value when the inertia controller is installed in WTG, the gain takes values related with the physical inertia constant of the rotating components. However, when the concept of inertia controller is applied to BESS, the physical understanding is lost, and as a consequence, any value could be used but consideration about the rate of discharge of the battery must be taken into account. A sudden high discharge current that can lead to excessive heat build-up and thermal runaway.

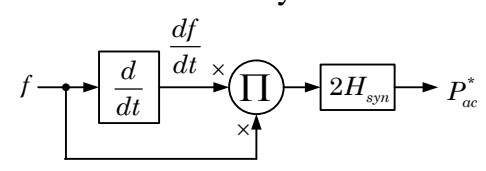

Fig. 8. Block diagram of the of the frequency controller [11].

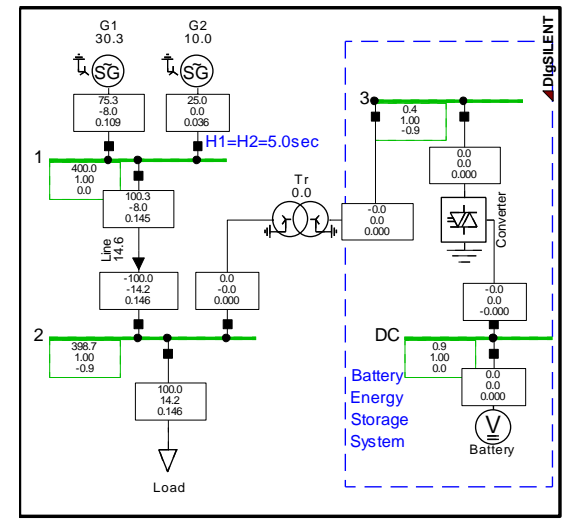

Fig. 9. Test System considering a 50 MW BESS.

\section{SIMULATIONS AND RESULTS}

This section presents simulations and results of the system frequency response of a test system including a BESS with inertia control. All the controllers presented in Section III has been implemented using DIgSILENT Simulation Language [12] (DSL) and time-domain simulations using DIgSILENT PowerFactory 2016 SP2 [13] are used to evaluate the system frequency response. The original model of the BESS was taken from the PowerFactory application manual "Battery Energy Storing Systems in PowerFactory" [14, 15], the author modifies it in order to cope with the research purposes and also, including the inertial response controller. MATLAB ${ }^{\circledR}$ has been using for post-processing purposes.

\section{A. Test System description}

Fig. 9 shore the illustrative Test System, it consists of two synchronous generators $\left(H_{1}=H_{2}=5.0 \mathrm{sec} @\right.$ MVA) connected to a load using an overhead transmission line. The BESS is connected on the demand busbar (see Fig. 9). The system frequency disturbance consist of the sudden disconnection of generator $G_{2}$, as a consequence the power imbalance is $\Delta P_{T}=$ $P_{G 2}$. Generators are equipped with the governor (GAST model) and AVR (IEEE Type I).

\section{B. Test I: Inertia response analysis}

Initially, the total demand $\left(P_{L}=100 \mathrm{MW}\right)$ is shared between the two generators $\left(P_{G 1}=75 \mathrm{MW}, P_{G 2}=25 \mathrm{MW}\right)$. Fig. 10 and 11 show the system frequency response without (Case $A)$ and with inertial response enabled (Case $\left.B, H_{s y n}=50\right)$ in the BESS respectively. The initial SOC is assumed 0.8 in all simulations.

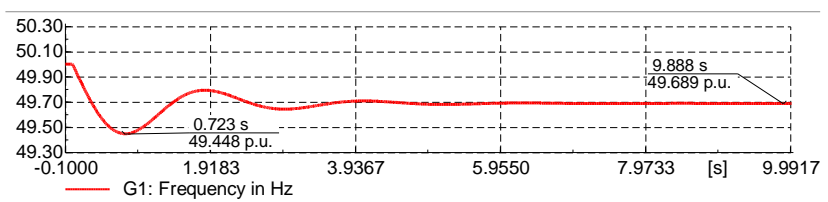

Fig. 10. Case A: System frequency response, without inertial response of the BESS, $\Delta P_{T}=25 \mathrm{MW}, G_{I}$ has GAST model, Droop $=5 \%$.

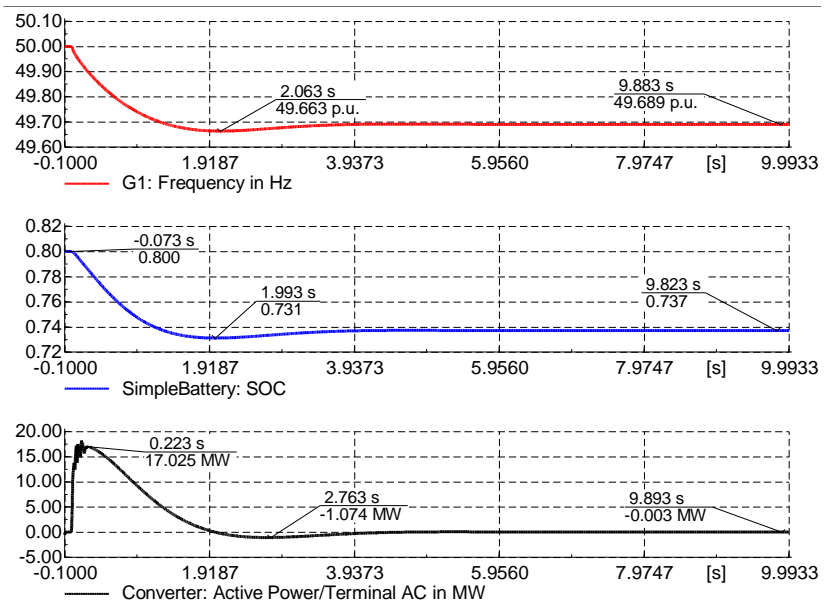

Fig. 11. Case B: System frequency response, with inertial response $H_{s y n}=-50$ sec of the BESS, $\Delta P_{T}=25 \mathrm{MW}, G_{l}$ has GAST model, Droop $=5 \%$.

When the inertial response is enabled on the BESS (Case $B)$, the inertial power $\left(\Delta P_{\max }=17 \mathrm{MW} @ 0.223 \mathrm{sec}\right)$ contribution during the system frequency disturbance helps to improve the transient frequency response, the $R o C o F$ is reduced from $\sim 1.2 \mathrm{~Hz} / \mathrm{s}$ (Case A) to $0.23 \mathrm{~Hz} / \mathrm{s}$ (Case B). The minimum frequency $\left(f_{\min }\right)$ is increased on Case $B\left(f_{\min }=49.663\right.$ $\mathrm{Hz}$ ), however, $f_{\min }$ is reached in a longer time $(2.063 \mathrm{~s})$ compared with the Case A (0.723s). As expected, the inertial controller has no effect on the steady-state frequency $\left(f_{s s}=\right.$ $49.689 \mathrm{~Hz}$ in both cases). This illustrative simulation shows the advantages of using the inertial controller in BESS to reduce the initial drop in the system frequency, allowing time to the 
low inertia synchronous generators to provide frequency response. However, and interesting aspect of the inertial controller presented in this paper is the fact the battery is discharged in $\sim 8 \%$ at the end of the system frequency disturbance. The critical point here, the charge control is allowing the battery to recharge during critical stages of the frequency response. Fig. 11 shows how the BESS take power from the power system, $\Delta P=-1 \mathrm{MW} @ 2.7 \mathrm{~s}$, during the frequency transient. This is especially dangerous because it can create a second system frequency disturbance triggering an unstable frequency dynamic.

\section{Test II: Sensibility of $H_{\text {syn }}$}

This Test shows how the system frequency response is improved when the gain of the synthetic inertial controller of the BESS is increased. In this case, $H_{s y n}$ is changed from 0 until 1000 .
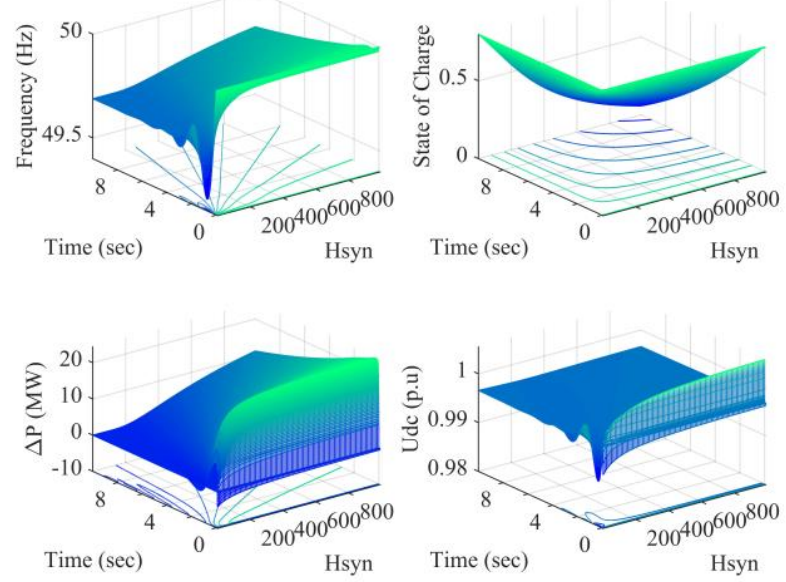

Fig. 12. System frequency response considering changes on the gain of the inertia controller $H_{s y n}$ of the BESS, $\Delta P_{T}=25 \mathrm{MW}$.

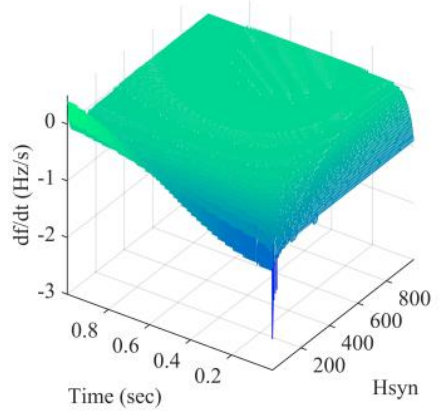

Fig. 13. Simulation results of Test II: $R o C o F$ versus $H_{s y n}$.

Fig 12 shows the performance of the main electromechanical-chemical variables involved in the system frequency response. Fig. 13 shows how the changes on the $R o C o F$ are especially high at very low values of $H_{s y n}$, however, further increases in the gain of the synthetic inertia controller has not major effects on the $\mathrm{RoCoF}$

\section{CONCLUSIONS}

This paper presents a simple controller to enable the inertial response of utility-scale battery energy storage system (BESS) on grid level transmission system in order to support fast inertial frequency response. Simulations results demonstrated the appropriate performance of the inertial controller presented in this paper.

\section{REFERENCES}

[1] ENTSO-e. (2016). Frequency Stability EvaluationCriteria for the Synchronous Zone of Continental Europe - Requirements and impacting factors -. Available: https://docs.entsoe.eu/tr/dataset/inertia-reportcontinental-europe/resource/148d6b97-4fb9-4eaa-8977-124e581ddd1c

[2] National Grid Plc. (2015). System Operability Framework. Available: http://www2.nationalgrid.com/UK/Industry-information/Future-ofEnergy/System-Operability-Framework/

[3] NG. (2010). National Grid, Grid Code Frequency Response Working Group: "Simulated Inertia". Available: http://www.nationalgrid.com/uk/Electricity/Codes/gridcode/workinggrou ps/freqresp/

[4] National Grid Plc. (2016). Security and Quality of Supply Standard (SQSS). Available: http://www.nationalgrid.com/uk/Electricity/Codes/gbsqsscode/

[5] National Grid Plc. (2015). The Grid Code. Available: http://www2.nationalgrid.com/uk/industry-information/electricitycodes/grid-code/the-grid-code/

[6] National Grid Plc. (2015). Future Energy Scenarios. Available: http://www2.nationalgrid.com/UK/Industry-information/Future-ofEnergy/Future-Energy-Scenarios/

[7] UK Power Networks. (2013). Smarter Network Storage. Available: http://innovation.ukpowernetworks.co.uk/innovation/en/Projects/tier-2projects/Smarter-Network-Storage-(SNS)/

[8] AES UK \& Ireland. (2015). Kilroot Advancion® Energy Storage Array. Available: http://aesukireland.com/our-business/energy-storage/kilrootenergy-storage/default.aspx

[9] M. Ceraolo, "New dynamical models of lead-acid batteries," IEEE Transactions on Power Systems, vol. 15, pp. 1184-1190, 2000.

[10] F. Gonzalez-Longatt, "Frequency Control and Inertial Response Schemes for the Future Power Networks," in Large Scale Renewable Power Generation, J. Hossain and A. Mahmud, Eds., ed: Springer Singapore, 2014, pp. 193-231.

[11] F. Gonzalez-Longatt, A. A. Bonfiglio, R. Procopio, and B. Verduci, "Evaluation of Inertial Response Controllers for Full-Rated Power Converter Wind Turbine (Type 4)," presented at the IEEE PES General Meeting 2016, Boston, USA, 2016.

[12] F. Gonzalez-Longatt and J. Rueda, PowerFactory Applications for Power System Analysis: Springer-Verlag, 2014.

[13] DIgSILENT, "DIgSILENT PowerFactory 2016 SP2," 14.0.524.2 ed. Gomaringen, Germany, 2016.

[14] S. Barsali and M. Ceraolo, "Dynamical models of lead-acid batteries: implementation issues," IEEE Transactions on Energy Conversion, vol. 17, pp. 16-23, 2002.

[15] D. Kottick, M. Blau, and D. Edelstein, "Battery energy storage for frequency regulation in an island power system," IEEE Transactions on Energy Conversion, vol. 8, pp. 455-459, 1993. 